\title{
Modeling the trade-off between effective case management and imported malaria cases in different settings of $P$. falciparum malaria transmission intensity
}

\author{
Valerie Crowell, Diggory Hardy, Nakul Chitnis, Nicolas Maire, Thomas Smith \\ From Parasite to Prevention: Advances in the understanding of malaria \\ Edinburgh, UK. 20-22 October 2010
}

\section{Background}

In many settings, $P$. falciparum transmission has been greatly reduced due to scaled-up malaria control. Imported cases will continue to be a source of malaria infection when vector control operations are stopped. We investigate the level of surveillance and case management that must be achieved in order to maintain reduced transmission levels, considering a varying rate of importation of cases and initial entomological inoculation rate (EIR).

\section{Methods}

Simulations were carried out with a model ensemble based on a previously-published individual-based stochastic simulations of the natural history and epidemiology of $P$. falciparum malaria. As a reference we considered 1000 humans exposed to seasonal transmission based on a Tanzanian setting, with an initial EIR of two infectious bites per person per annum, and importation of infections at a rate of three per annum. Four annual rounds of indoor residual spraying were carried out at the beginning of the simulation and then stopped. Case management was simulated at varying coverages.

\section{Results}

We present the results of a range of simulated scenarios. Figure 1a illustrates the reference situation with minimal case management coverage. The black lines give the median incidence of locally acquired cases from 10 simulation runs of each of 15 different models and

Health Institute, Basel, Switzerland

\footnotetext{
Department of Epidemiology and Public Health, Swiss Tropical and Public
}

C 2010 Crowell et al; licensee BioMed Central Ltd. This is an open access article distributed under the terms of the Creative Commons Biomed Central parameterisations. The simulations suggest that, in this setting, malaria will resurge within several years. When case management eliminated $85 \%$ of secondary cases, clinical incidence remained negligible for the rest of the simulation period (Figure 1b)

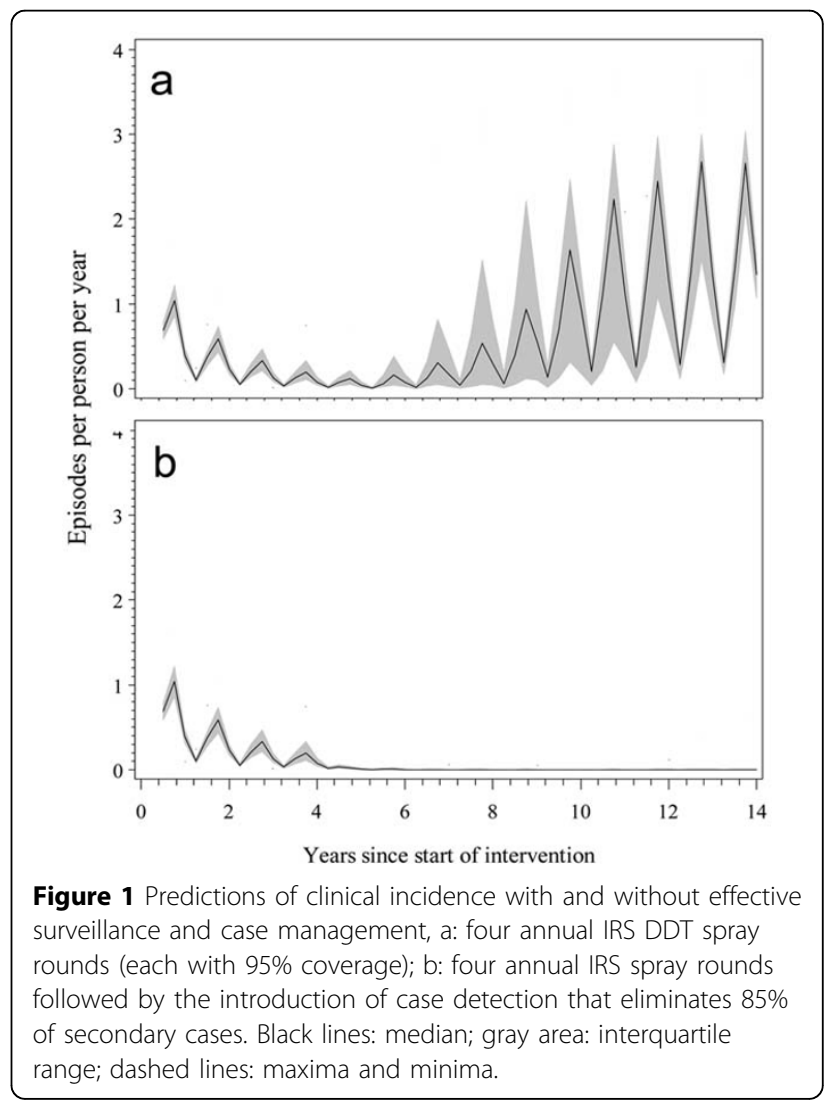




\section{Conclusion}

Initial results suggest that reductions in malaria transmission in many areas call for a strategy to deal with imported cases as a priority. In the absence of another transmission-blocking intervention, such as a vaccine, high coverage of case management will likely be critical to avoid resurgence of malaria.

Published: 20 October 2010

doi:10.1186/1475-2875-9-S2-P7

Cite this article as: Crowell et al:: Modeling the trade-off between effective case management and imported malaria cases in different settings of $P$. falciparum malaria transmission intensity. Malaria Journal 2010 9(Suppl 2):P7.

Submit your next manuscript to BioMed Central and take full advantage of:

- Convenient online submission

- Thorough peer review

- No space constraints or color figure charges

- Immediate publication on acceptance

- Inclusion in PubMed, CAS, Scopus and Google Scholar

- Research which is freely available for redistribution

Submit your manuscript at www.biomedcentral.com/submit 